\title{
Composite nanomaterials based on copper to replace silver in electrical contacts
}

\author{
Iosif S. Gershman ${ }^{1,2, a}$, Eugeniy I. Gershman ${ }^{1,2}$ and Pavel Yu. Peretyagin ${ }^{1}$ \\ 1 Laboratory of Electric Currents and Sintering Technologies (LECAST), Moscow State University of Technology "STANKIN" \\ Vadkovsky Pereulok 1, Moscow 127994, Russia \\ 2 Joint Stock Company "Railway Research Institute", 10, 3rd Mytischinskaya Street, Moscow 129851, Russia
}

Received 23 November 2016, Accepted 30 November 2016

\begin{abstract}
The article considers the substitution of silver in interrupting electrical contacts by a nonprecious metal on the basis of copper. Technical specifications for the material capable of replacing silver are formulated, including high softening temperature and weak adhesion of oxides to the base metal. As a result, a composite nanomaterial on the basis of copper is offered to substitute silver. Microstructure, mechanical, thermî-mechanical, physical properties of the nanocomposite was studied. Changes of contact resistance during the formation of oxides on the surfaces of copper, silver, and the nanocomposite was studied, as well as losses of volume when exposing these materials to an electric arc. The prospects of substituting silver by the nanocomposite on the basis of copper were proven by the results of comparative bench testing of materials.
\end{abstract}

Key words: Electrical contacts / silver / copper nanocomposite / properties / electric arc / wear / contact resistance

\section{Introduction}

Silver has the highest electrical and thermal conductivities among metals. Electrical and thermal conductivities of copper are only $6 \%$ less than that of silver. But copper cannot replace silver in interrupting electric contacts. In the situations when silver is used, copper is intensively worn out with deep damage to the contact zone. At the same time, silver cannot be subsituted in contacts by heat resistant low-alloy bronzes of $\mathrm{Cu}-\mathrm{Cr}, \mathrm{Cu}-\mathrm{Nb}, \mathrm{Cu}-\mathrm{Cr}-\mathrm{Nb}$, $\mathrm{Cu}-\mathrm{Cr}-\mathrm{Zr}, \mathrm{Cu}-\mathrm{Cr}-\mathrm{V}$ systems and arc-resistant electrotechnical composites on the basis of copper, for example materials of the $\mathrm{Cu}-\mathrm{W}$ system [1-4].

Table 1 shows main properties of copper and silver. Copper has better mechanical properties compared with silver, including under higher temperatures. Copper has higher melting and boiling temperatures as well as specific heat capacity than silver.

Consequently, all things being equal, copper needs more energy to heat, melt, evaporate and boil. Copper has a higher value of surface tension in a liquid state, consequently it moistens its solid substrate better. Therefore copper has higher erosion resistance and arc resistance than silver [5]. With virtually equal plasticity copper is stronger and harder than silver, consequently, all things

\footnotetext{
${ }^{a}$ Corresponding author: isgershman@gmail.com
}

being equal, copper will be less exposed to mechanical wear and fatigue failures. Besides copper has smaller density compared with silver, consequently, with equal volumes, the amount of copper needed will be $15 \%$ less than that of silver.

Thus, copper is better than silver in terms of its mechanical, thermo-mechanical and thermal properties and is only slightly behind silver in terms of electrical conductivity and thermal conductivity. Copper and silver have approximately the same dependencies of physical properties from temperatures. The only significant difference is the vapour pressure. Under the same temperature the vapour pressure of silver is much more than that of copper, which is not an advantage of silver as contact material. Copper not only has better mechanical properties but also a very high softening temperature even though it is close to that of silver.

According to technical requirements for electrical contacts allowable operational temperatures are around $75^{\circ} \mathrm{C}$ for copper and $200{ }^{\circ} \mathrm{C}$ and more for silver. Therefore thermal conductivity, electrical conductivity, mechanical and thermo-mechanical properties are not the defining factors for the use of silver in electrical contacts.

Such defining characteristics are rather thermodynamic properties of oxides of copper and silver. In terms 
I.S. Gershman et al.: Mechanics \& Industry 17, 708 (2016)

Table 1. Properties of silver and copper $[6,7]$.

\begin{tabular}{ccc}
\hline Properties & Copper & Silver \\
\hline Potential of atom ionization, eV & 7.724 & 7.574 \\
Density, $10^{3} \mathrm{~kg} . \mathrm{m}^{-3}$ & 8.933 & 10.499 \\
Specific thermal capacity at $288 \mathrm{~K}, \mathrm{~J} /(\mathrm{kg} . \mathrm{K})$ & 0.369 & 0.235 \\
Temperature of melting, K & 1357 & 1235 \\
Temperature of boiling, K & 2816 & 2440 \\
Melting heat , J.kg ${ }^{-1}$ & 205.7 & 104.9 \\
Sublimation heat at 298 K, J.kg ${ }^{-1}$ & 5319 & 2644 \\
Thermal conductivity at 300 K, W/(mK) & 401.2 & 432.5 \\
Thermal expansion coefficient at 300 K, 10 ${ }^{-6} \mathrm{~K}^{-1}$ & 16.61 & 18.8 \\
Coefficient of surface tension in liquid state, J.m ${ }^{-2}$ & 1.351 & 0.930 \\
Specific electrical resistance at 293 K, mkOhm.m & 0.0172 & 0,0162 \\
thermal coefficient electrical resistance at $273 \mathrm{~K}, \mathrm{~K}^{-1}$ & 0.0043 & 0.0041 \\
Temporary tensile resistance, MPa & 265 & 177 \\
Relative elongation, $\%$ & 60 & 65 \\
Hardness, HB & 41 & 25 \\
\hline
\end{tabular}

of these properties copper and silver are significantly different from one another.

Table 2 shows thermodynamic characteristics of copper and silver oxides, in particular free energy of their formation [8].

Thermodynamic properties (Tab. 2) are the only properties that are significantly different for copper and silver. It was already shown above that in terms of their mechanical, thermomechanical, physical properties copper and silver are not much different. Therefore one can assume the reason why copper cannot be used at higher temperatures as opposed to silver.

If there are arcing contacts in the contactor in addition to main contacts, then at disconnecting no arc is formed between the main contacts. When using copper contacts with increased currents and temperature, thick layers of hard oxides are formed on their working surfaces. Due to significant growth of transient resistance high temperature develops in the contact. As the result of the formation of a thick layer of oxides the contact may interrupt commutation. At higher temperatures the base metal softens, deforms, and oxides will be falling off along the base metal. As the result the working surface gets deeply damaged and quickly wears out.

Oxides on silver contacts, according to the data from Table 2, are thermodynamically unstable at increased temperatures. That is why silver contacts can be used at high currents and increased temperatures.

\section{Requirements for promising materials for interrupting electrical contacts instead of silver}

In addition to traditional requirements to physical, mechanical and thermo-mechanical properties, electrical contact materials aimed at replacing silver-based materials are to meet requirements related to instability of the oxides on the working surfaces. Since copper has specific electrical conductivity which is only $6 \%$ less than that of silver, only copper can be the base contact material instead of silver.

However, thermodynamically stable oxides are formed on copper. Therefore, a material is needed without a strong adhesion of oxides to the substrate. Such materials can be dispersion reinforced copper composites with very finely dispersed particles.

At the same time the material should have its heat resistance as high as possible with very high starting softening temperature of at least $700{ }^{\circ} \mathrm{C}$. This requirement is necessary in order to remove oxides not along the substrate material but along the border between this materials and the oxides.

Specific electrical resistance of the proposed material is not to be lower than specific electrical resistance of the most common material based on silver Ag-15\% CdO, which is $0.028 \mathrm{mkOhm} . \mathrm{m}$ (at least $62 \%$ IACS) [9].

The hardness should be no less than $80 \mathrm{HB}$, to provide the necessary strength, but not to exceed $160 \mathrm{HB}$ in order not to significantly reduce the contact area.

Such requirements are met by dispersion reinforced materials on the basis of copper with the size of dispersed inclusions of no more than $100 \mathrm{~nm}$.

When exposed to an arc the material must not lose volume more than copper does.

\section{Materials and methods}

In the experiments, the following materials were used: silver Ag 99.99, cold-rolled copper Grade S11000. Composite material Cu-1 \% volume $\mathrm{Al}_{2} \mathrm{O}_{3}$. Production of composite included the following main process steps: smelting of $\mathrm{Cu}-\mathrm{Al}$ alloy, turning alloy into chips, oxidation of copper, reduction of copper by oxidizing aluminum, processing of the material in a ball mill, hot pressing of prebriquetted powder.

Specific electrical resistance, hardness, tensile strength were measured for the materials $[2,10,11]$. These properties were determined at $20^{\circ} \mathrm{C}$ before and after holding at $800{ }^{\circ} \mathrm{C}$ and at $900{ }^{\circ} \mathrm{C}$. The temperature of softening was 
Table 2. Standard free energy of formation of silver and copper oxides. Temperature dependence of free energy of oxides formation $\left(10^{-3} \mathrm{~kJ} . \mathrm{mol}^{-1}\right)$, temperatures of melting and boiling.

\begin{tabular}{ccccc}
\hline Temperature, $\mathrm{K}$ & $\mathrm{Cu}_{2} \mathrm{O}$ & $\mathrm{CuO}$ & $\mathrm{Ag}_{2} \mathrm{O}$ & $\mathrm{Ag}_{2} \mathrm{O}_{2}$ \\
\hline 298 & 148.4 & 129.2 & 10.5 & -27.6 \\
400 & 140.9 & 119.8 & 3.8 & -45.6 \\
600 & 126.6 & 101.7 & -8.58 & - \\
800 & 112.8 & 84.4 & -20.5 & - \\
1000 & 99.4 & 67.2 & -32.2 & - \\
1200 & 86.5 & 50.9 & - & - \\
1400 & 73.3 & 35.6 & - & - \\
1600 & 57.4 & 18 & - & - \\
Temperature of melting, K & 1515 & 1609 & 460 & - \\
Temperature of boiling, K & 2073 & - & - & - \\
\hline
\end{tabular}

determined according to the results of hardness measurement before and after holding the material for an hour at this temperature. Above $700{ }^{\circ} \mathrm{C}$ the holding temperature was increased by $20{ }^{\circ} \mathrm{C}$ increments.

Tests to determine the material volume loss when exposed to an arc were carried out in a DC arc with a single exposure to the arc discharge. The arc was initiated between the pair of contacts made of the same material. The current in the arc is $2.5 \mathrm{kA}$, the total arc time was $180 \mathrm{~ms}$, the initial distance between contacts $-10 \mathrm{~mm}$. Weight loss of contacts was measured. Volume loss was determined by dividing the weight loss by material density. Figure 1 shows the dependence of current and voltage in the arc on the arc time.

To determine the electrical resistance of oxide films on the contact materials, three samples of the materials were kept at $200{ }^{\circ} \mathrm{C}$ in the air for $1 \mathrm{~h}, 3 \mathrm{~h}, 5 \mathrm{~h}, 7 \mathrm{~h}$ and 10 . After each time period voltage drop across the oxide films (contact voltage) at a current of 100 A was determined. Then the electrical resistance (contact resistance) was calculated.

Bench tests were carried out on the contactor at a voltage of $50 \mathrm{~V}$, a current of $1250 \mathrm{~A}$. The tests determined the comparative wear of contact materials made of copper and of the nanocomposite $\mathrm{Cu}-\mathrm{Al}_{2} \mathrm{O}_{3}$ as well as change of transient contact resistance.

For comparison with the wear of contacts made of silver Ag-CdO composite and nanocomposite $\mathrm{Cu}-\mathrm{Al}_{2} \mathrm{O}_{3}$, bench tests were carried out on the contactor at a voltage of $1500 \mathrm{~V}$ and a current of $1300 \mathrm{~A}$.

Microstructural studies were conducted on the TEM [13-15].

\section{Results and discussion}

Microstructural studies of the composite carried out using TEM showed that the size of the subgrains (Fig. 1) were in the range of 100-150 microns.

This means that the composite is hard-drawn and has relatively fine subgrains [16]. Figure 2 shows an image of the carbon replica of the composite. The average size of the dispersed particles of $\mathrm{Al}_{2} \mathrm{O}_{3}$ is about $30 \mathrm{~nm}$. At the same time, they occupy a large surface area - of about

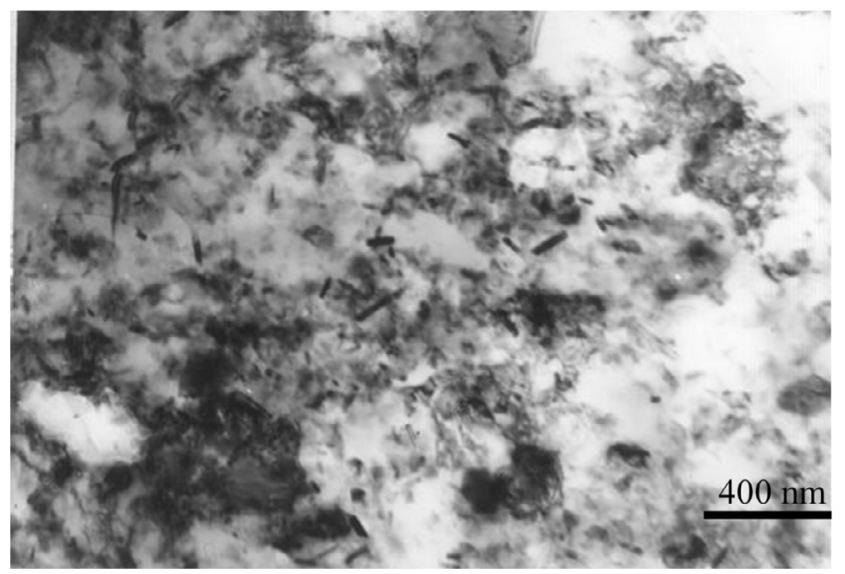

Fig. 1. Subgrain structure of the nanocomposite $\mathrm{Cu}-\mathrm{Al}_{2} \mathrm{O}_{3}$.

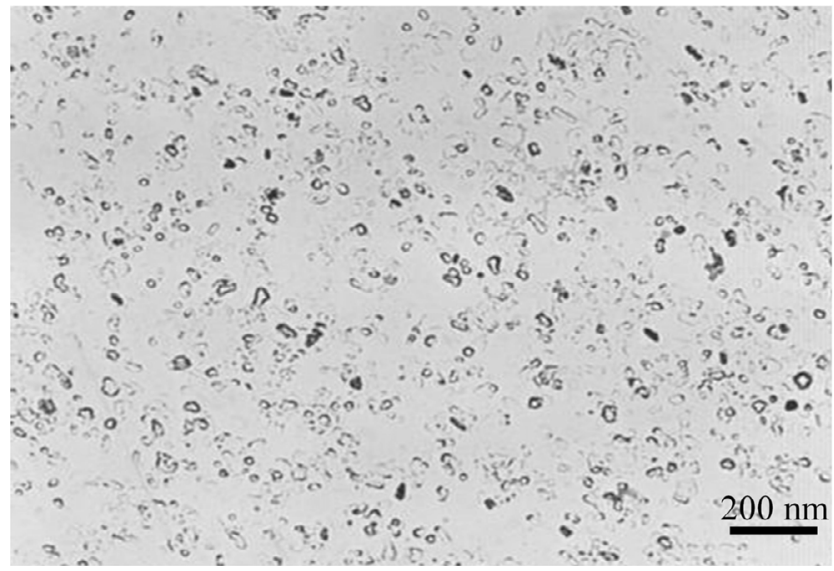

Fig. 2. Carbon replica of the nanocomposite $\mathrm{Cu}-\mathrm{Al}_{2} \mathrm{O}_{3}$.

$20 \%$. This increases the softening temperature and reduces the adhesion of the oxide film to the surface of the composite. Dimensions of dispersed particles are of the nanocomposite category $[17,18]$.

Mechanical properties, specific electrical conductivity before and after an hour of annealing at $800{ }^{\circ} \mathrm{C}$, as well as softening temperature are shown in Table 3.

Volume losses after exposure of the materials to the electrical arc are shown in Figure 3. 
I.S. Gershman et al.: Mechanics \& Industry 17, 708 (2016)

Table 3. Properties of materials in original state/after annealing at $800^{\circ}$.

\begin{tabular}{cccccc}
\hline Material & $\begin{array}{c}\text { Specific electrical } \\
\text { conductivity (IACS) }\end{array}$ & $\begin{array}{c}\text { Tensile strength } \\
\text { at } 20{ }^{\circ} \mathrm{C}(\mathrm{MPa})\end{array}$ & $\begin{array}{c}\text { Hardness } \\
(\mathrm{HB})\end{array}$ & $\begin{array}{c}\text { Tensile strength at } \\
900{ }^{\circ}(\mathrm{MPA})\end{array}$ & $\begin{array}{c}\text { Temperature of } \\
\text { softening, }{ }^{\circ} \mathrm{C}\end{array}$ \\
\hline $\mathrm{Cu}-\mathrm{Al}_{2} \mathrm{O}_{3}$ & $81 / 87$ & $461 / 430$ & $130 / 130$ & $176 / 176$ & 860 \\
\hline $\mathrm{Cu}$ & $100 / 100$ & $357 / 218$ & $112 / 44$ & $14.4 / 14.4$ & 210 \\
\hline
\end{tabular}

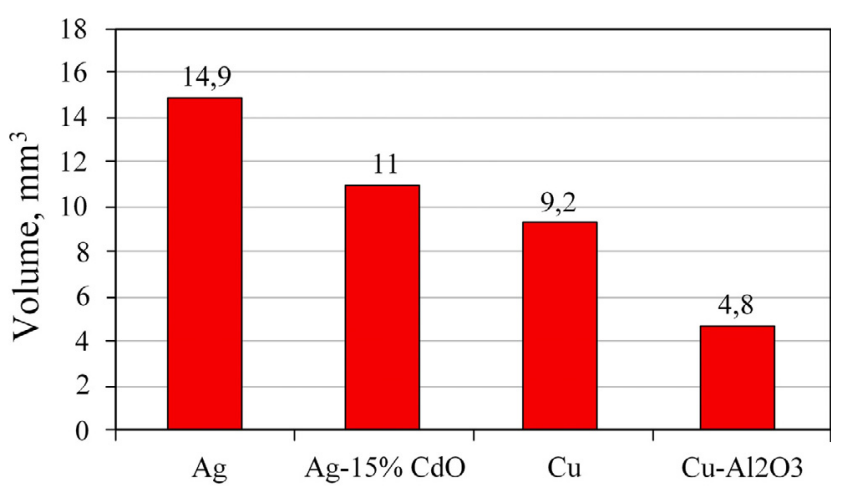

Fig. 3. Material volume loss after exposure to an electric arc.

Figure 4 shows the dependence of the contact resistance of silver, copper, $\mathrm{Cu}-\mathrm{Al}_{2} \mathrm{O}_{3}$ nanocomposite on the exposure time at $200{ }^{\circ} \mathrm{C}$.

Test results show that the $\mathrm{Cu}-\mathrm{Al}_{2} \mathrm{O}_{3}$ nanocomposite has better strength and hardness compared with copper. The nanocomposite is not significantly inferior to copper in terms of conductivity. However, the value of the electrical conductivity of the nanocomposite is greater than the electrical conductivity of the composite Ag-CdO.

The main result of the tests is a much higher softening temperature of the nanocomposite compared to the softening temperature of copper. It should be noted that the softening temperature of the $\mathrm{Cu}-\mathrm{Al}_{2} \mathrm{O}_{3}$ nanocomposite exceeds the softening temperature of the known heat resistant low-alloy copper alloys. The nanocomposite has a high heat resistance with by an order of magnitude higher strength than the strength of copper at $900^{\circ} \mathrm{C}$. This may indicate the increased resistance of the nanocomposite $\mathrm{Cu}-\mathrm{Al}_{2} \mathrm{O}_{3}$ to mechanical wear at high temperatures.

Figure 4 shows that when exposed to an electric arc the nanocomposite loses several times less volume than copper, silver and composite $\mathrm{Ag}-\mathrm{CdO}$.

The nanocomposite $\mathrm{Cu}-\mathrm{Al}_{2} \mathrm{O}_{3}$ has a reduced contact resistance in comparison with copper (Fig. 4). This confirms the assumption that relatively unstable oxides are formed on the contact surface.

Check of impact of the formation of oxides on the contact resistance and the wear process was carried out during bench tests. The results of the bench tests of contacts from different materials are given in Table 4.

Even though the initial contact resistance of copper is almost two times smaller than that of the nanocomposite, the final contact resistance of copper is almost 2 times greater than that of the nanocomposite. Wear of copper contacts is approximately 2.5 times higher than the wear of the nanocomposite contacts. Thus, the formation of

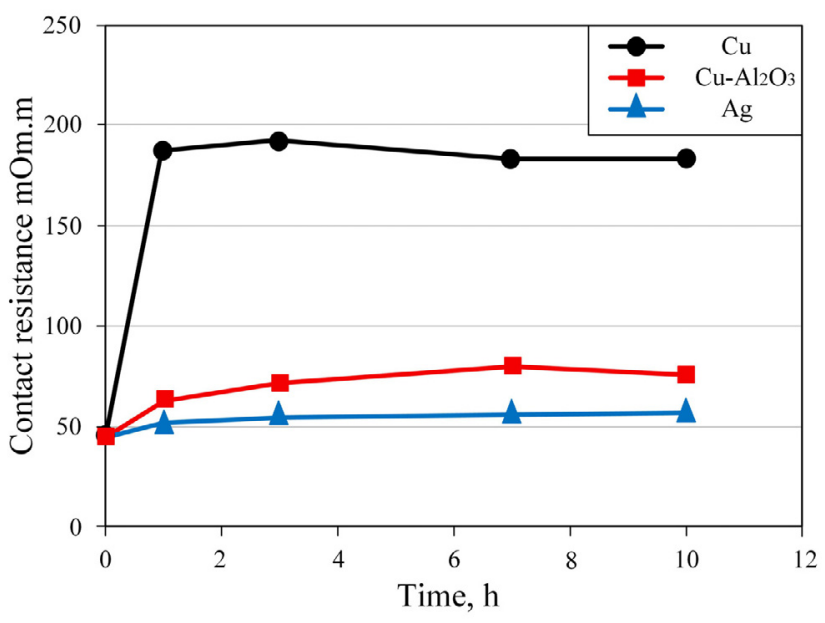

Fig. 4. Dependence of the contact resistance of materials on annealing time at $200{ }^{\circ} \mathrm{C}$.

mechanically unstable oxides on the surface of samples of the nanocomposite $\mathrm{Cu}-\mathrm{Al}_{2} \mathrm{O}_{3}$ ensures reliable work of electrical contacts during operation.

The results of bench tests for comparison with silver contacts are shown in Table 5 .

Contacts of the nanocomposite $\mathrm{Cu}-\mathrm{Al}_{2} \mathrm{O}_{3}$ are not worn as intensively as the contacts from the composite $\mathrm{Ag}-\mathrm{CdO}$.

Thus, less intensive wear of the electrical contacts from the nanocomposites compared with copper is due to the high softening temperature and the formation of oxides on the surface of the nanocomposite with a weak bond with the substrate.

In operation, the surface of electrical contacts gets deformed. Copper has a softening temperature below that of the operating zone, that is why annealing occurs at its surface. Directly at the surface of a layer, annealed copper about 300 microns thick is formed, capable of seazure during the subsequent curcuit of electrical contacts. Upon subsequent disconnection of the electrical contacts particles are torn from one of the surfaces to the depth of up to 500 microns. Nanocomposite $\mathrm{Cu}-\mathrm{Al} 2 \mathrm{O} 3$ in contrast to pure copper has a high softening temperature (800$\left.860^{\circ} \mathrm{C}\right)$. Therefore, annealing may not occur in this case, it is hardened to a depth of 200 microns. Surface particles of two meeting electrical contacts are set together to a much lesser extent.

Oxides formed on the surface of copper electrical contacts are resistant and have a good bond with the base material. When such contacts are curcuit it partially offsets oxides deforming the base material. Subsequent curcuits destroy these areas (oxides are torn deeply damaging 
I.S. Gershman et al.: Mechanics \& Industry 17, 708 (2016)

Table 4. Results of bench test at the voltage of $50 \mathrm{~V}$, current $1250 \mathrm{~A}$.

\begin{tabular}{cccccc}
\hline \multirow{2}{*}{ Material } & \multicolumn{3}{c}{ Contacts } & \multicolumn{2}{c}{ Contact resistance, mOhm } \\
\cline { 3 - 6 } & \multirow{2}{*}{\begin{tabular}{c}
$\mathrm{Cu}$ \\
\cline { 3 - 6 }
\end{tabular}} & $\begin{array}{c}\text { Location } \\
\text { fixable }\end{array}$ & $\begin{array}{c}0.273 \\
\text { fixear of contacts, } \mathrm{g}\end{array}$ & Before testing & After testing \\
\hline \multirow{2}{*}{2} & $\mathrm{Cu}-\mathrm{Al}_{2} \mathrm{O}_{3}$ & $\begin{array}{c}\text { Movable } \\
\text { fixed }\end{array}$ & $\begin{array}{c}0.118 \\
0.078\end{array}$ & 0.072 & 0.472 \\
\hline
\end{tabular}

Table 5. Comparative wear of contacts from the nanocomposite $\mathrm{Cu}-\mathrm{Al}_{2} \mathrm{O}_{3}$ and composite $\mathrm{Ag}-\mathrm{CdO}$.

\begin{tabular}{ccc}
\hline Material of contacts & Position & Wear of contacts, $\mathrm{mm}^{3}$ \\
\hline \multirow{2}{*}{$\mathrm{Ag}-\mathrm{CdO}$} & Movable & 2.8 \\
& Fixed & 2.5 \\
\hline \multirow{2}{*}{$\mathrm{Cu}-\mathrm{Al}_{2} \mathrm{O}_{3}$} & Movable & 2.7 \\
& Fixed & 1.9 \\
\hline
\end{tabular}

the base material). The situation is complicated by a relatively low temperature of softening of copper.

Oxides are formed on the surface of electrical contacts from the nanocomposite $\mathrm{Cu}-\mathrm{Al}_{2} \mathrm{O}_{3}$, and their bonding to the base material is much weaker than that of copper. That is why they separate themselves from the base material of electrical contacts during subsequent disconnections and curcuits.

\section{Conclusion}

The softening temperature of the nanocomposite is more than $800{ }^{\circ} \mathrm{C}$. The cooper nanocomposite durability is better than the silver durability in the breaking electric contacts.

The nanocomposite is not behind the silver from the durability point of view thanks to its high softening temperature and weak oxides adhesion to the basic material.

$\mathrm{Cu}-\mathrm{Al}_{2} \mathrm{O}_{3}$ cooper based nanocomposite is able to substitute silver in the breaking electric contacts including those of the power plants of the heavy industry, transport, space industry for the currents more up to 1200 À, in particular for switching engines cooling systems.

Acknowledgements. The Ministry of Education of the Russian Federation supported this work by contract No. 14.577.21.0199, a unique identifier of contract RFMEFI57715X0199.

The work is carried out on the equipment of the Center of collective use of MSTU "STANKIN".

\section{References}

[1] Y. Ziqin, J. Chengchang, G. Le, Zh. Jun, X. Zizhang, A microstructure of allows $\mathrm{W}-\mathrm{Cu}$, fabricated by mechanical activation, Univ. Sci. Techn 24 (2002) 115-118

[2] C. Guo-Qin, W. Gao-Hui, Z. De-Zhi, Z. Qiong, J. LongTao, Microstructure and thermal and electric conductivities of high dense $\mathrm{Mo} / \mathrm{Cu}$ composites, Trans. Nonferrous Metals Soc. 15 (2005) 110-114
[3] C. Hui, W. Ya-Ping, Z. Zhi, X. Ai-Ping, Properties of $\mathrm{CuCr}$ contact materials with low chromium content and fine particles, Trans. Nonferrous Metals Soc. 13 (2003) 930-932

[4] B. Xiao-Qin, H. Rui, L. Jinshan, Zh. Qi, F. Heng-Zhi, Evolution of microstructure of natural composites $\mathrm{Cu}-$ Cr, Mater. Sci. Tecnol. 13 (2005) 153-157

[5] K. Wang, Q Wang, Erosion on silver-base material contacts by breaking arcs, IEEE Trans. 14 (1991) 293-297

[6] M. Braimov, V.V. Konchits, N.K. Myshkin, Electrical Contacts: Fundamentals, Applications and Technology CRC Press, New York, 2006

[7] G. Paul, Slade Electrical Contacts: Principles and Applications, CRC Press, 2013

[8] Thermodynamic properties of elements and oxides, U.S. Bureau of Mines, 1982

[9] K.H. Schroder, Silver-metal oxides as contact materials, IEEE Trans. 10 (1987) 127-134

[10] C.F. Gutierrez-Gonzalez, M. Suarez, S. Pozhidaev, S. Rivera, P. Peretyagin, W. Solis, L.A. Diaz, A. Fernandez, R. Torrecillas, Effect of TiC addition on the mechanical behavior of $\mathrm{Al} 2 \mathrm{O} 3-\mathrm{SiC}$ whiskers composites obtained by SPS, J. Eur. Ceramic Soc. 36 (2016) 2149-2152

[11] I. Alvarez, R. Torrecillas, W. Solis, P. Peretyagin, A. Fernandez, Microstructural design of Al2O3-SiC nanocomposites by Spark Plasma Sintering, Ceramics Int. 42 (2016) 17248-17253

[12] L.A. Diaz, W. Solis, P. Peretyagin, A. Fernandez, M. Morales, C. Pecharroman, J.S. Moya, R. Torrecillas, Spark Plasma Sintered Si3N4/TiN Nanocomposites Obtained by a Colloidal Processing Route, J. Nanomater. 2016 (2016) 1-9

[13] L.A Díaz, M.A. Montes-Moran, P.Y. Peretyagin, Y.G. Vladimirov, A. Okunkova, J.S. Moya, R. Torrecillas, Zirconia-alumina-nanodiamond composites with gemological properties, J. Nanoparticle Res. 16 (2014) 2257

[14] E. Fernandez-Garcia, C.F. Gutierrez-Gonzalez, P. Peretyagin, W. Solis, S. Lopez-Esteban, R. Torrecillas, A. Fernandez, Effect of yttria-titanium shell-core structured powder on strength and ageing of zirconia/titanium composites, Mater. Sci. Eng. A 646 (2016) 96-100

[15] L. Fernández-García, M. Suárez, J.L. Menéndez, C. Pecharromán, R. Torrecillas, P.Y. Peretyagin, J. Petzelt, M. Savinov, Z. Frait, Antiresonance in (Ni, Zn) ferritecarbon nanofibres nanocomposites, Mater. Res. Express 5 (2015) 055003 
[16] S.V. Novikov, P.Yu. Peretyagin, E.Yu. Dolzhikova, R. Torrecillas, Formation of Structure in Hard-Alloy Coatings from Powders Under Passage of a Powerful Pulse of Electric Current, Metal Sci. Heat Treatment 57 (2016) 596-602

[17] M.A. Volosova, A.A. Okunkova, D.E. Povolotskiy, P.A. Podrabinnik, Study of electrical discharge machining for the parts of nuclear industry usage, Mechanics \& Industry 16 (2015) 706
[18] L.A. Díaz, A. Fernández, A. Okunkova, W. Solís, P. Peretyagin, F.J. Gotor, R. Torrecillas, Electro Conductive Alumina Nanocomposites From Different Alumina-Carbides Mixtures, MATEC Web of Conferences 65 (2016) 02003

[19] N.W. Solis, P. Peretyagin, A. Seleznev, R. Torrecillas, J.S. Moya Black zirconia-graphene nanocomposite produced by spark plasma sintering, AIP Conf. Proc. 1785 (2016) 040074 